Online Resources for Music Entrepreneurship

Music Entrepreneurship is a field on the rise. What might have once been covered under the umbrella of "music business" is now a formally recognized program at many institutions. Often these programs are designed to complement the undergraduate curriculum by creating an elective track in entrepreneurship or a certificate program. Students in entrepreneurship look to combine their love of music with a desire to support themselves financially outside of the traditional music employment structures. This could be anything from forming a touring band to perform one's own compositions to founding a music academy to teach lessons to disadvantaged students. In every situation, an analysis of the market and industry is required to understand the challenges and opportunities inherent in a new venture. The following resources are some of the best places to begin that process.

\title{
Mintel http://www.academic.mintel.com
}

Mintel bills itself as "the world's leading market intelligence agency, with offices in London, Chicago, Shanghai, Belfast, Kuala Lumpur, Mumbai, Munich, New York, São Paulo, Singapore, Sydney, Tokyo and Toronto." What is does is collect massive amounts of data on markets (people buying things), and present both the data and analysis in digestible formats. Mintel organizes its content around reports. These reports serve to present the state of any given market sector, like the streaming media market in the US, analyze multiple data points, and indicate to the reader where opportunities lie. Each report is compiled by a single market analyst who can be contacted directly.

Reports include a variety of documents, which can vary from one report to the next. These include an executive summary, infographic, Power Point slides, Excel spreadsheet with all referenced data, and Report Brochure (a teaser document that outlines the report without displaying content. It clearly indicates the price of the report for non-academic users purchasing reports individually). Some reports also include a social media overview (information collected via social media). All of these options are great for the user, as it gives him or her the flexibility to crunch the numbers themselves or reuse already packaged slides. Mintel is excellent if one if looking for detailed information on the purchasing habits of different generations.

\section{IBISWorld http://www.ibisworld.com}

Both IBISWorld and Mintel can be black holes of exploration because of the richness of the data and analysis they provide. IBISWorld markets itself as " the United States' most comprehensive collection of Industry Market Research and Industry Risk Ratings." It is widely used in Business both in the classroom and in the field. It is a report-structured database that excels at bringing an individual from zero knowledge about an industry (people selling things) to understanding the supply chain, supplying industries, demand industries, related industries, key players, barriers to entry, primary activities of the industry, major products and services, and industry jargon. All of these sections are visually connected, so one can easily navigate from one report 
to another. Anyone considering starting a business would benefit from the research in this database.

\section{RIAA Reports Archive https://www.riaa.com/reports/}

The Recording Industry Association of America (RIAA) is the major trade organization of the music industry. It's membership consists of dues-paying record companies. According to the RIAA, "nearly $85 \%$ of all legitimate recorded music produced and sold in the United States is created, manufactured or distributed by RIAA members." The RIAA is the organization that certifies sales status, like gold or platinum, and it also conducts industry and consumer research, which it disseminates for free. The sales data provided by the RIAA is hard to find anywhere else, and their reports package the information well. Here one can discover what percentage of the market synchronization royalties capture, how quickly digital subscriptions are growing, and how much money people are paying for ringtones. Also, this is the place to settle once and for all how "major" of a comeback LPs are having. The main reports the RIAA produces are the U.S. Consumer Music Profile and the Year-End Sales and Shipments Data. The information in the Consumer Music Profile shows what formats are purchased by age range as well as favorite genres by format buyers (for example, the majority of CD purchasers identify classic rock as their favorite genre). The Year-End Sales and Shipments reports show purchasing trends across all sound platforms. Researchers can clearly get a sense of trends in music purchasing with this data.

\section{Social Explorer http://www.socialexplorer.com/}

Finally, Social Explorer is a subscription database that enables users to interact with current and historical demographic data in a visual way. Primarily, this is through mapping. Social Explorer has fantastic mapping tools that go from the neighborhood to the national level. It has a sideby-side comparison tool so users can look at multiple maps at once. It has a login feature so maps can be saved and funneled into presentations using the Storyboard tool. This gives users the ability to integrate maps, audio, images, and video into a multimedia presentation. Projects can be saved in one's account and shared on social media. The type of demographic data included in Social Explorer is diverse. It includes categories like marital status, occupation, type of housing, income, family structure, travel time to work, unemployment, and the list goes on. I used this database to assist a student in identifying an ideal site for her business venture, in which she was looking for two types of neighborhoods that bordered each other in a specific city. Social Explorer was the perfect resource for the task.

Stephanie Bonjack

Howard B. Waltz Music Library

University of Colorado Boulder

Boulder, $\mathrm{CO}$ 